\title{
Large Scale Electrical Resistivity Tomography Survey Correlated to Hydrogeological Data for Mapping Groundwater Salinization: A Case Study from a Multilayered Coastal Aquifer in Rhodope, Northeastern Greece
}

\author{
Evangelos C. Galazoulas • Yannis C. Mertzanides • \\ Christos P. Petalas • Evangelos K. Kargiotis
}

Received: 7 November 2014 / Accepted: 19 January 2015 /Published online: 7 February 2015

(C) Springer International Publishing Switzerland 2015

\begin{abstract}
A large scale two dimensional electrical resistivity survey was carried out to investigate groundwater salinization phenomena of a multilayered coastal aquifer in south Rhodope area, northeastern Greece. The electrical resistivity tomography (ERT) profiles, calibrated with lithological, physicochemical and geophysical log data, were used to demarcate the geometry of the aquifer system and characterize the extent of the interface between saline and freshwater in a coastal groundwater system, which has been subject to overexploitation for the last 35 years. In total, 12 deep high resolution ERT profile lines, covering a distance of approximately $15 \mathrm{~km}$ were carried out at key locations across the downgraded part of the aquifer system. The resistivity sections were calibrated using a reference dataset of 45 information wells incorporating 28 lithological logs, 31 groundwater quality samples from a variety of screen placements and five gamma ray logs. Results revealed the presence of four major resistivity zones ranging in values between 0.1 and $150 \Omega \mathrm{m}$ at various depths and locations. A very low resistivity zone $(0.1-5 \Omega \mathrm{m})$ correlated with saline water saturated layers, a medium resistivity zone $(5-15 \Omega \mathrm{m})$ attributed to clays and silts, and two high resistivity zones generally representing freshwater saturated sediments of coarse grain size $(15-40 \Omega \mathrm{m})$ or alterations of thin marl and fine sand layers $(40-150 \Omega \mathrm{m})$. It is demonstrated that extensive use of high resolution deep geoelectrical sections, calibrated with a large number of hydrogeological data can successfully delineate aquifer geometry dimensions, identify hydraulic boundaries and clarify ambiguous field measurements, thus allowing the development of a thorough hydrogeological conceptual model.
\end{abstract}

$\overline{\text { E. C. Galazoulas }(\bowtie) \cdot \text { C. P. Petalas }}$

Laboratory of Ecological Engineering and Technology, Department of Environmental Engineering, Democritus University of Thrace, Xanthi, GR 67 100, Greece

e-mail: egalazou@env.duth.gr

Y. C. Mertzanides • E. K. Kargiotis

Hephaestus Laboratory, Department of Petroleum and Mechanical Engineering, Eastern Macedonia and Thrace Institute of Technology, Kavala, GR 65404, Greece 
Keywords Electrical resistivity tomography $($ ERT) - Geophysical mapping · Groundwater salinization · Multilayered coastal aquifer

\section{Introduction}

The overexploitation of groundwater resources in coastal aquifers, along with the subsequent saltwater intrusion, result to the degradation of the natural ecosystems (Ranjan et al., 2006), with severe socioeconomic effects on local communities, through the decline in freshwater availability and the reduction of agricultural productivity (Beltran, 1999; Tuong et al., 2003; Pisinaras et al., 2010). Therefore, the need for a thorough aquifer system description and continuous quality monitoring is crucial in every coastal zone, in order to construct a sustainable groundwater management scheme and to implement appropriate regulatory policies. According to Bear et al. (1999), there are two fundamental sources of information in groundwater saline intrusion investigations, the hydrochemical and the geophysical methods. Data acquired with these techniques separately, or ideally coupled together, can successfully delineate the freshwater/saltwater interfacial configuration in a coastal aquifer system. Among them, the geophysical methods present significant advantages over the geochemical ones, since they involve lower cost and less time in their application (Maillet et al., 2005). Another critical advantage is that they are non-destructive and that they incorporate the ability to produce continuous datasets over large areas, while geochemical analyses are limited only to points of interest where boreholes exist (Martínez et al., 2009).

The last 15 years, geophysicists and hydrologists worked hand-in-hand in order to identify subsurface structures and understand flow processes inside aquifer systems. This interdisciplinary approach offered new tools and advanced knowledge to hydrological studies and has developed a unique subdiscipline called «Hydrogeophysics» (Rubin and Hubbard, 2005). Out of the variety of surface geophysical methods applied in groundwater studies, direct current electrical methods consist one of the primarily preferred in saline environments due to their inherent ability to detect formation resistivity variations based on pore water salinity (Barker, 1990; Abdul Nassir et al., 2000; ASTM, 2011). Geoelectrical methods are executed by measuring the electrical potential arising from an artificially injected current, with the purpose of achieving information about the near surface underground resistivity distribution (Telford et al., 1990). Recent developments in this field, both in data acquisition as well as in inverse modeling techniques, have allowed the transition from the limited, one dimensional form of Vertical Electrical Soundings (VES) to the more complex and pretentious two or three dimensional Electrical Resistivity Tomography (ERT) technique (Dahlin, 2001). Various researchers are found in the literature, exploiting direct current geoelectrical methods competence in groundwater salinization investigations around the world. Examples of one dimensional soundings include: Urish and Frohlich (1990); Frohlich et al. (1994); Ebraheem et al. (1997); Nowroozi et al. (1999); Choudhury et al. (2001); Edet and Okereke (2001); Sherif et al. (2006); and Adepelumi et al. (2009). In all the aforementioned studies, the authors were able to successfully distinguish between freshwater and saltwater domains in various geological environments, by combining the results of numerous Vertical Electrical Soundings (VES) across coastal zones.

Over the last decades, due to the rapid development of computer processing speed and data acquisition systems, the ERT technique has evolved rapidly and numerous applications are present in saline environments. In certain occasions (Wilson et al., 2006), the ERT technique was used in order to supplement and clarify the results of initially executed one dimensional VES in the same region. The efficiency of the ERT technique in a variety of inshore geological 
settings is demonstrated by various researchers, including coastal alluvial aquifers (Abdul Nassir et al., 2000; Morrow et al., 2010; Ebraheem et al., 2012; Mas-Pla et al., 2012), coastal deltaic deposits (Maillet et al., 2005; Martínez et al., 2009; Gurunadha Rao et al., 2011), or inland saline environments, e.g., in the Okavango Delta, Botswana (Bauer et al., 2006), in the Dead Sea, Jordan aquifer (Batayneh, 2006), and in Querenca-Silves, south Portugal (Leitão et al., 2014). These authors have utilized various array configurations and electrode spacing intervals, and showed that the method is able to provide a good correlation between specific resistivity values and hydrogeological properties, and thus, to calculate formation factors (Archie, 1942) for the separate aquifer units, by combining groundwater electrical resistivity measurements and bulk formation resistivity distribution. This way, it was made possible to successfully demarcate saltwater/freshwater interface and to identify aquifer dimensions (basement depth and lateral extent) for a diversity of geological settings.

More recent ERT applications comprise time-lapse measurements in monitoring salinization phenomena. de Franco et al. (2009) monitored seawater intrusion in Venice lagoon, Italy and managed to correlate the resistivity alterations with various environmental variables (e.g., rainfall, groundwater recharge and tidal regime), while Ogilvy et al. (2009) used a similar setting in the Andarax River, Spain to map and monitor saltwater intrusion with greater confidence and efficiency, compared to traditional methods. Additionally, Zarroca et al. (2011) compared the results of preexisting VES with modern ERT traverses to characterize saline intrusion progress in the Alt Emporda region, Spain. Finally, the efficiency of the method is highlighted by its extensive use in saline tracer monitoring examples (Singha and Gorelick, 2005; Cassiani et al., 2006; Hermans et al., 2012; Perri et al., 2012) where the twodimensional direct current geoelectrical method was used to monitor the evolution of an artificially injected plume through time and space.

In this study, a large scale ERT survey was carried out, in a multilayered coastal aquifer located in the southeastern Rhodope province, northeastern Greece, to supplement the hydrogeological investigation of the area (Petalas, 1997). The potential of the geophysical method used, was evaluated in a complex multilayered aquifer system for which hydrogeological information has been acquired over the last 25 years. The aim of this paper is to present the results of the geophysical survey mentioned above, to evaluate the ERT technique as an imaging tool in salinization phenomena over multilayered coastal aquifers, and to emphasize the importance of interdisciplinary approach on the study of such complex hydrogeological problems.

\section{Materials and Methods}

\subsection{Study Area Description}

The study area is located in the south part of the Eastern Macedonia and Thrace Region in North Greece, and consists part of a broader aquifer system deployed in the Rhodope Regional Division coastal zone (Fig. 1a). Over-exploitation of local groundwater resources due to an extensive agricultural use, has led to a remarkable groundwater drawdown and saltwater intrusion (Petalas, 1997). Geographical limits, delineated with dotted line in Fig. 1a, were chosen based on hydrogeological and hydrochemical criteria in order to enclose the saline intruded portion of the aquifer and to represent natural or artificial groundwater flow boundaries. Significant surface hydrological features include the numerous lagoons dominating the coastal zone and two rivers, Kompsatos and Aspropotamos, located at the North discharging 


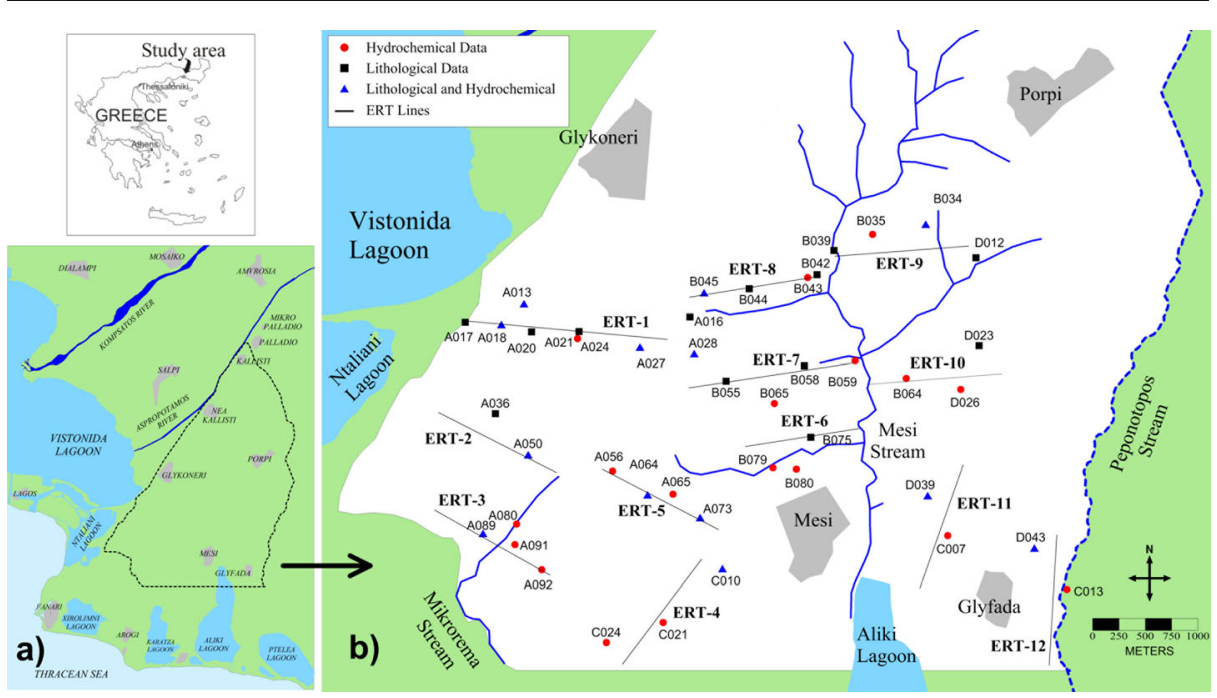

Fig. 1 a Study area location and position of ERT lines; b position of ERT lines calibration wells and main streams in the area

into Vistonis lagoon. The main economic activity of the local settlements is agriculture and livestock farming.

\subsection{Geological and Hydrogeological Setting}

The geological structure and hydrogeological conditions were investigated in the past by: Petalas (1997); Petalas and Diamantis (1999); Petalas and Lambrakis (2006); Petalas et al. (2009). A normal fault sited along the Glykoneri-Palladio axis separates the Plio-Pleistocene alluvial fan of Kompsatos river sediments at the northeast and the Upper Miocene continental deposits at the southwest. The latter consist of coarse alluvial unconsolidated sediments (sands, gravels and cobbles) deposited in a braided-river environment and fine lacustrine sediments (clays and silts). A continuous thick layer of green plastic clay, deposited at the base of this sequence marks the transition to older age formations consisting mainly of clays, silts and thin sand layers. Two main aquifers can be identified in the Upper Miocene deposits. A shallow semi-confined aquifer depicting an average thickness of $35 \mathrm{~m}$ along with limited hydraulic properties, and a thicker $(50-100 \mathrm{~m})$ confined aquifer which holds the major local groundwater reserves. Additionally, below the thick green clay unit, sand lenses interbedded between clays, marls and silts form a discontinuous isolated confined aquifer system.

Figure 2a shows the hydraulic head distribution and groundwater flow directions for the confined aquifer, using a monitoring network of 25 observation wells during April 2012. The piezometric surface is well below mean sea level, with higher values across the fault line and lower at the east. It appears that groundwater from the adjacent alluvial fan of Kompsatos river aquifer system laterally recharges the confined aquifer along two major axes, one close to the Nea Kallisti village and one south of Glykoneri. Groundwater flow lines converge to Porpi village where a cone of depression is formed. The low hydraulic gradient east of Mesi denotes either the existence of higher hydraulic conductivity sediments (Todd, 1980) or the location of a vertical recharge zone, which prevents piezometric drawdown. In Fig. 2b, the spatial distribution of electrical conductivity for the confined aquifer is presented. It is apparent that 


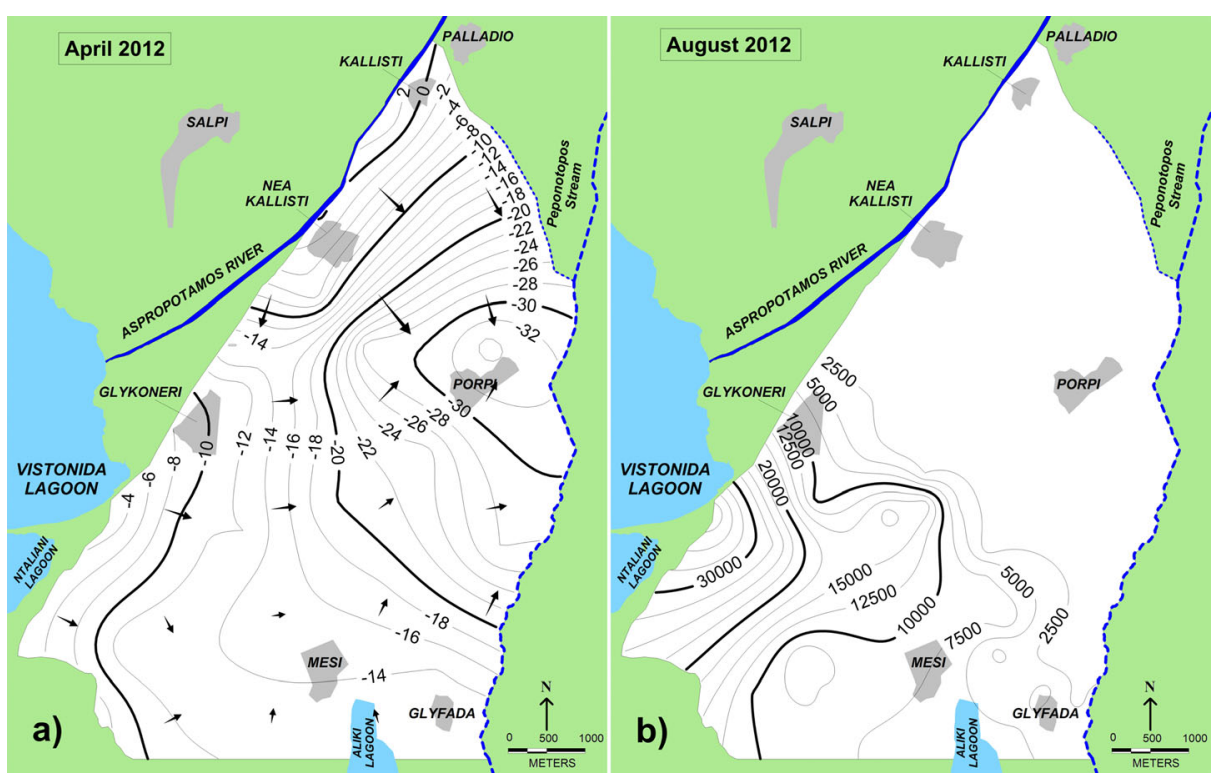

Fig. 2 a Piezometric map and flow paths for the confined aquifer during April 2012; b Distribution of electrical conductivity values for the confined aquifer during August 2012

the previously identified recharge axis south of Glykoneri allows saline groundwater to enter the system and progress eastward. The origin of the saltwater is from a phreatic aquifer located underneath Vistonis lagoon and vertically recharged by it (Petalas, 1997). Electrical conductivity measurements generally exceed $1 \mathrm{mS} / \mathrm{cm}$ at the largest portion of the study area, reaching a maximum of $45 \mathrm{mS} / \mathrm{cm}$ close to the inlet of Vistonis lagoon. Numerous wells are drilled in the area, penetrating either the shallow semi-confined aquifer or the main confined aquifer or both, thus allowing groundwater transfer through well screens and mixing of different quality water masses. In the recent years, due to the rapid saltwater intrusion progress and the depletion of freshwater resources (Petalas and Lambrakis, 2006; Petalas et al., 2009; Galazoulas and Petalas, 2014), various wells have been drilled at greater depths, penetrating the deep aquifer system located underneath the main confined aquifer.

\subsection{Electrical Resistivity Tomography Survey}

The electrical resistivity geophysical survey was designed according to the spatial distribution of borehole, physicochemical and piezometric data, and was carried out between December 2011 and May 2013. The ERT lines locations are shown in Fig. 1b. The first lines were selected either in well investigated locations with much hydrogeological information available or at locations with absence of adequate data. The existing hydrogeological datasets consist of: (i) continuous piezometric and physicochemical measurements; (ii) a dense network of lithological profiles from wells drilled in the area; (iii) a significant level of information derived from geophysical well loggings (gamma ray logs). The extreme salinization taking place over the largest part of the area favors the selection of the geoelectric method, which is highly sensitive in high groundwater salinity contrasts. Although a large amount of data is available, there is a high degree of uncertainty regarding the origin and distribution of saline facies, because of the complexity of the aquifer system. It is important to note that high salinity groundwater was pumped from 
inland wells even before the piezometric drawdown initiation, indicating the presence of saline connate water masses trapped in the sediments. Aquifer system complexity is enhanced by human activities, such as improperly constructed wells and the lack of proper managing and supervising policies implemented. Complete calibration of ERT profiles resulted in detailed mapping of underground structures and processes taking place in the system, like natural recharge zones, freshwater/saltwater mixing and boundary conditions delineation. For this reason, in this study geophysical traverses are not focused solely on the freshwater/ saltwater interface boundary but fully cover the downgraded part of the aquifer in the horizontal and vertical axes, trying to capture all of the hydrogeological processes taking place in the complex coastal aquifer system.

Key planning parameters for the ERT lines placement were the confirmation of aquifer boundaries, the proximity to hydrogeological information points, the interference with surface hydrological features, the clarification of lithological or hydrochemical anomalies identified in the pre-existing datasets, the investigation of aquifer zones where no reliable data exist, the delineation of the saltwater/freshwater interface, the coverage of the entire downgraded area, and finally, the avoidance of uncrossable obstacles along the survey line (main roads, rivers, streams, lagoons). Based on these criteria, lines 1, 2, 3, 4, 11 and 12 were deployed perpendicularly to the aquifer western and southern limit to investigate the lateral recharge conditions and aquifer layer geometry. Maximum hydrogeological neighboring information was achieved in line 1, where 8 information wells incorporating all the available sources were available close to the survey line. Additionally, lines 3, 11 and 12 were placed in areas where not sufficient calibration data exists. ERT lines 5, 6, 7 and 8 are located inland to cover the full area extent and to explain ambiguous and confusing measurements in the pre-existing dataset. Finally, profiles 9 and 10 were deployed at the eastern edge to investigate the saltwater/freshwater interface and to delineate the saltwater intrusion extent.

The resistivity data were acquired using the ABEM TERRAMETER LS instrument, a 4channel system with the ability to handle 64 electrodes, a transmitter of $250 \mathrm{~W}, 2.5 \mathrm{~A}$ and $600 \mathrm{~V}$, and four cables of 21 take-outs that were used in the field work. The Dipole-Dipole array was used, due to the adequate depth of investigation and sensitivity to horizontal changes in resistivity caused by the lateral saline intrusion (Reynolds, 2011). The apparent resistivity for this array is given by the following Eq. (1):

$$
\rho_{\alpha}=\pi \cdot n \cdot(n+1) \cdot(n+2) \cdot \alpha \cdot R
$$

where:

$\alpha$ is the dipole length;

$n$ is the dipole separation factor; and

$R$ is the resistance value measured.

In this survey, the electrode spacing was $15 \mathrm{~m}$ and totally twelve high resolution deep electrical resistivity profiles were conducted. The typical survey line was $1200 \mathrm{~m}$ long and the roll-along technique was used in order to extend the section covered up to $1800 \mathrm{~m}$ length. The datasets of the apparent resistivity measured in the field gave the resistivity pseudo-sections. The real resistivity sections resulted after the pseudo-sections were inverted and with some pre-inversion and post-inversion handling. The RES2DINV program, by GEOTOMO SOFTWARE, was used, following the standard least-squares smoothness-constrained inversion formulation, $\left(\mathrm{L}_{2}\right.$-norm) and the complete Gauss-Newton optimization method (Loke and Barker, 1996). 


\section{Results and Discussion}

\subsection{ERT Data Analysis}

Table 1 illustrates the characteristics of the ERT profile lines presented in this study. Preprocessing of the initial dataset resulted in the exclusion of unrealistic high or low apparent resistivity measurements from the inversion process. The excluded values consisted of less than $1 \%$ of the total initial dataset for all the lines. The Root Mean Square (RMS) error values obtained during the minimization of the square difference between the observed and the calculated apparent resistivity values, varied between 2.6 and $13.8 \%$ over all ERT lines, indicating the good quality of measured data. The highest values of RMS errors were calculated for the profiles measured on summer, when the soil was very dry, while the lowest during the wet months. The highest RMS error was $13.8 \%$ and came from a survey line of $1800 \mathrm{~m}$ length, a dataset of 1641 measurements, conducted on 11th of August (the most dry days of the year). In total, 15,135 m of deep ERT profiles length were acquired and 16,737 data points of apparent resistivity measurements were measured.

\subsection{Resistivity Sections Interpretation}

Figures 3, 4, 5 and 6 show the two-dimensional resistivity models produced by the inversion of the twelve resistivity pseudo-sections, along with the projection of all the available hydrogeological data on top of the inverted sections. The ERT data were compared to drilling, well $\log$ and groundwater electrical conductivity data, in order to calibrate the $2 \mathrm{D}$ resistivity models and build a thorough conceptual model for the area of study. For every calibration point, the distance between the reference well and the section is shown, in order to establish a better level of calibration liability. For wells with unknown construction properties, a black arrow indicates only well location, while for every pumping well the range of electrical conductivity values measured during the irrigation period is shown. Finally, the main confined aquifer top and bottom limits are shown along with the groundwater piezometric surface for the main confined aquifer.

Table 1 Characteristics of the 12 ERT profile lines

\begin{tabular}{|c|c|c|c|c|c|c|c|c|}
\hline $\begin{array}{l}\text { Survey } \\
\text { line }\end{array}$ & $\begin{array}{l}\text { Date of } \\
\text { measurement }\end{array}$ & $\begin{array}{l}\text { Array } \\
\text { configuration }\end{array}$ & $\begin{array}{l}\text { Electrode } \\
\text { spacing }(\mathrm{m})\end{array}$ & $\begin{array}{l}\text { No of } \\
\text { electrodes }\end{array}$ & Length (m) & $\begin{array}{l}\text { No of } \\
\text { data points }\end{array}$ & $\begin{array}{l}\text { No of } \\
\text { iterations }\end{array}$ & $\begin{array}{l}\text { RMS } \\
\text { error }\end{array}$ \\
\hline ERT-1 & Aug-2012 & Dip.-Dip. & 15 & 121 & 1800 & 1641 & 5 & $13.8 \%$ \\
\hline ERT-2 & Mar-2013 & Dip.-Dip. & 15 & 81 & 1200 & 1460 & 5 & $5.4 \%$ \\
\hline ERT-3 & Apr-2013 & Dip.-Dip. & 15 & 81 & 1200 & 1469 & 5 & $3.9 \%$ \\
\hline ERT-4 & Apr-2013 & Dip.-Dip. & 15 & 81 & 1200 & 1469 & 5 & $3.2 \%$ \\
\hline ERT-5 & Mar-2013 & Dip.-Dip. & 15 & 80 & 1185 & 1423 & 5 & $2.6 \%$ \\
\hline ERT-6 & Apr-2013 & Dip.-Dip. & 15 & 71 & 1050 & 1122 & 5 & $7.1 \%$ \\
\hline ERT-7 & Apr-2013 & Dip.-Dip. & 15 & 101 & 1500 & 1763 & 5 & $4.7 \%$ \\
\hline ERT-8 & Dec-2011 & Dip.-Dip. & 15 & 81 & 1200 & 1090 & 5 & $9.5 \%$ \\
\hline ERT-9 & Feb-2013 & Dip.-Dip. & 15 & 81 & 1200 & 1349 & 5 & $5.2 \%$ \\
\hline ERT-10 & Apr-2013 & Dip.-Dip. & 15 & 81 & 1200 & 1314 & 4 & $9.6 \%$ \\
\hline ERT-11 & Apr-2013 & Dip.-Dip. & 15 & 81 & 1200 & 1332 & 5 & $5.2 \%$ \\
\hline ERT-12 & May-2013 & Dip.-Dip. & 15 & 81 & 1200 & 1305 & 4 & $10.1 \%$ \\
\hline
\end{tabular}



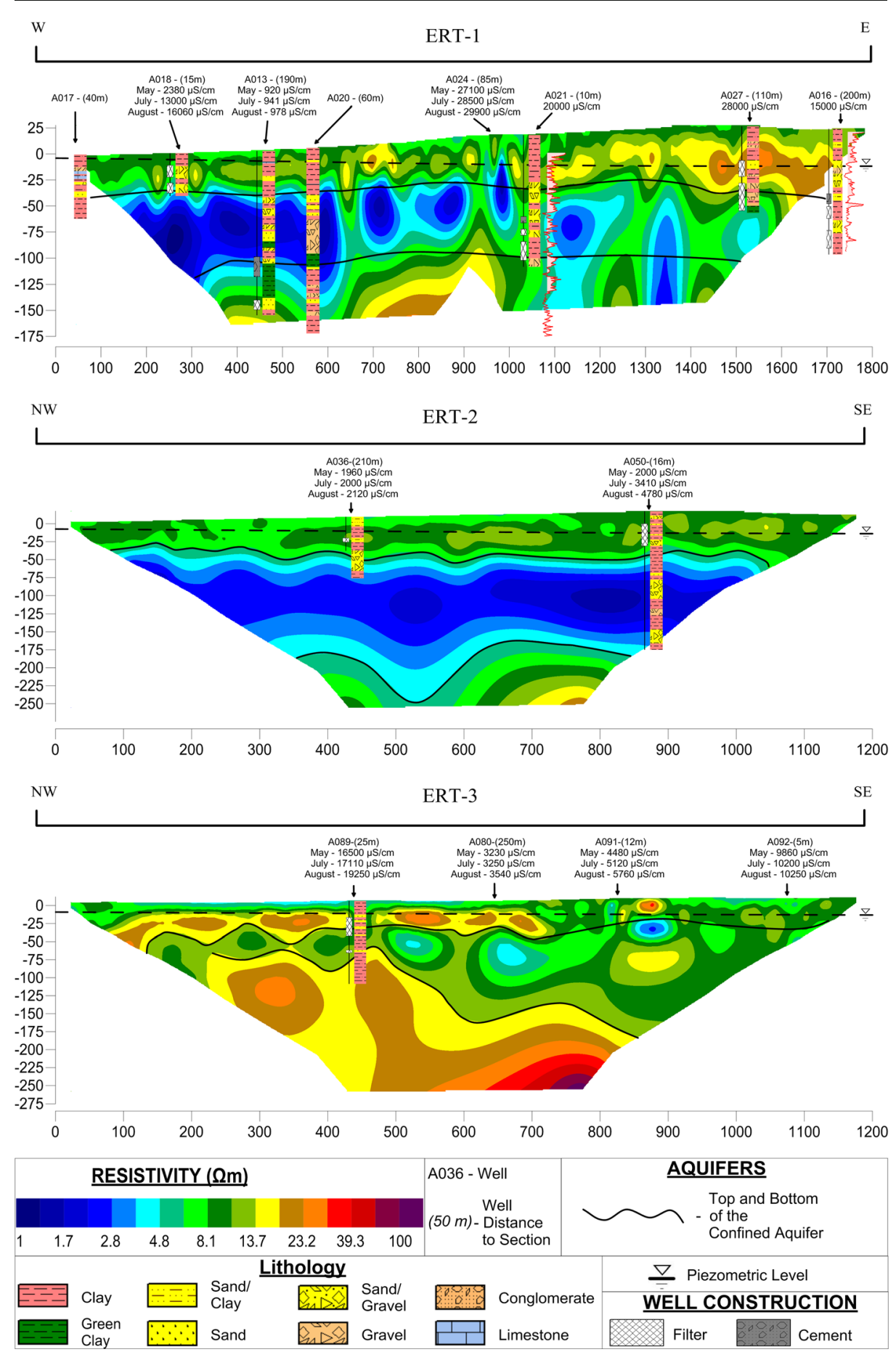

Fig. 3 Geoelectrical sections ERT1, ERT2 and ERT3 

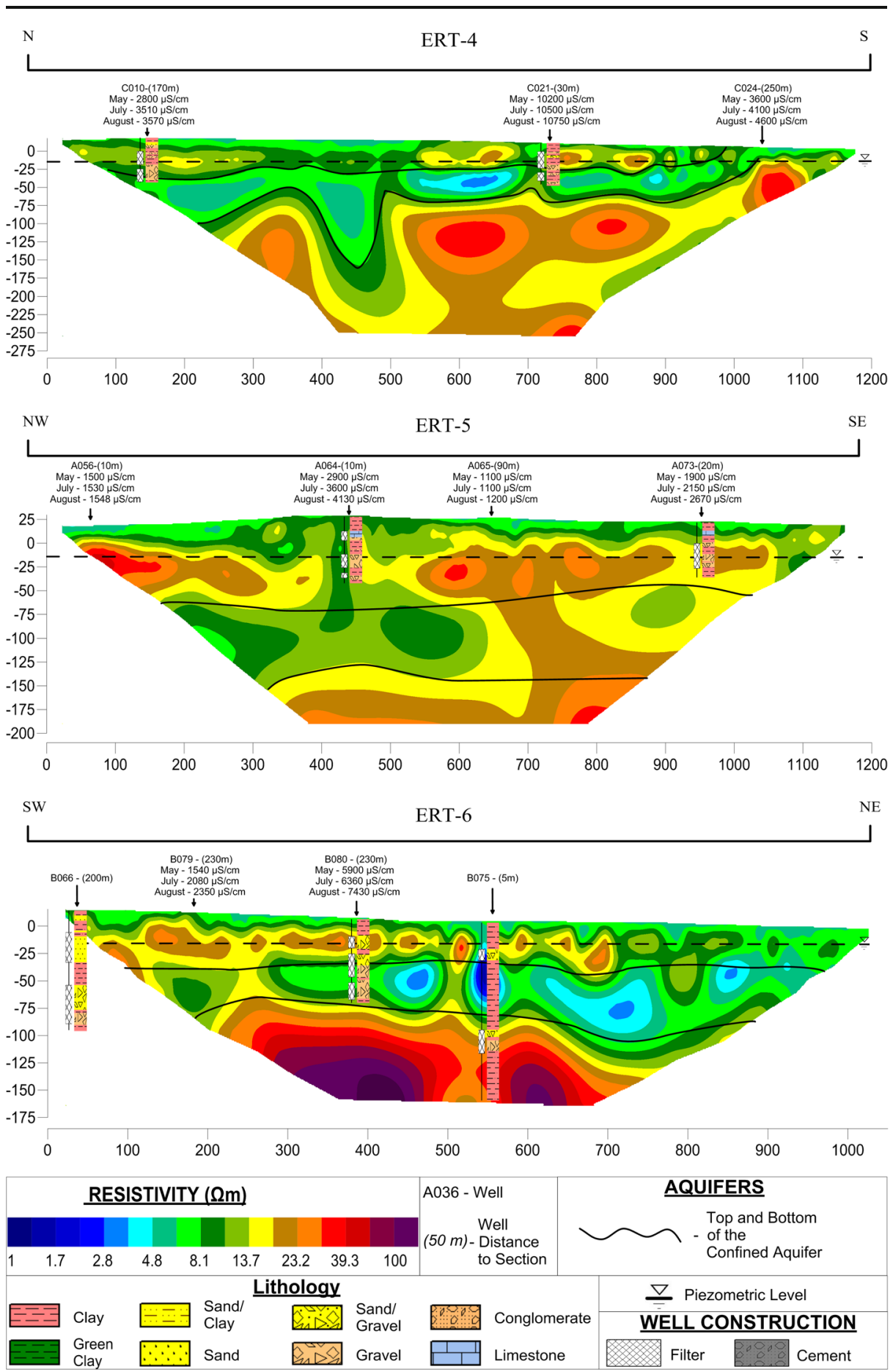

Fig. 4 Geoelectrical sections ERT4, ERT5 and ERT6 


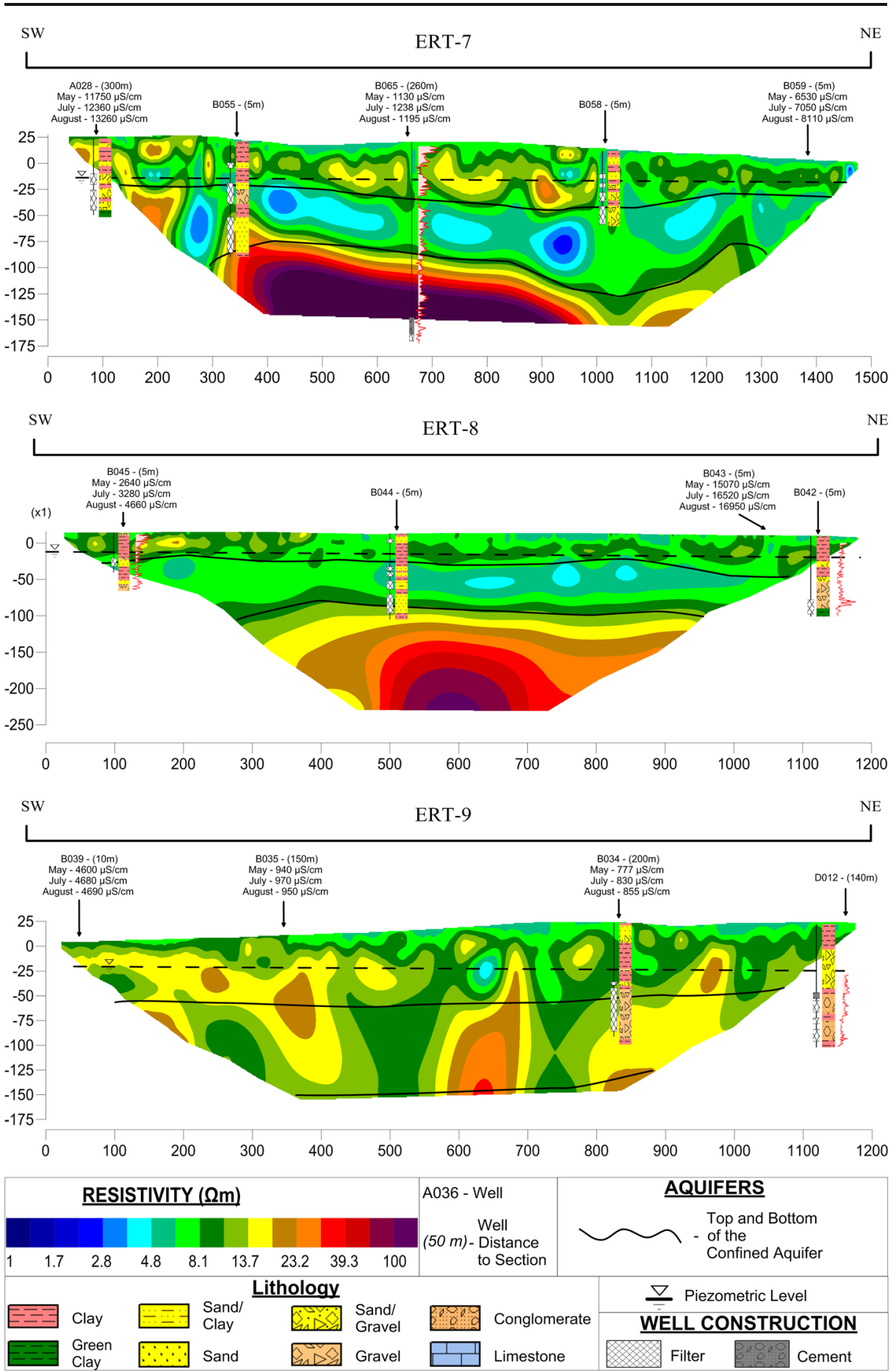

Fig. 5 Geoelectrical sections ERT7, ERT8 and ERT9 


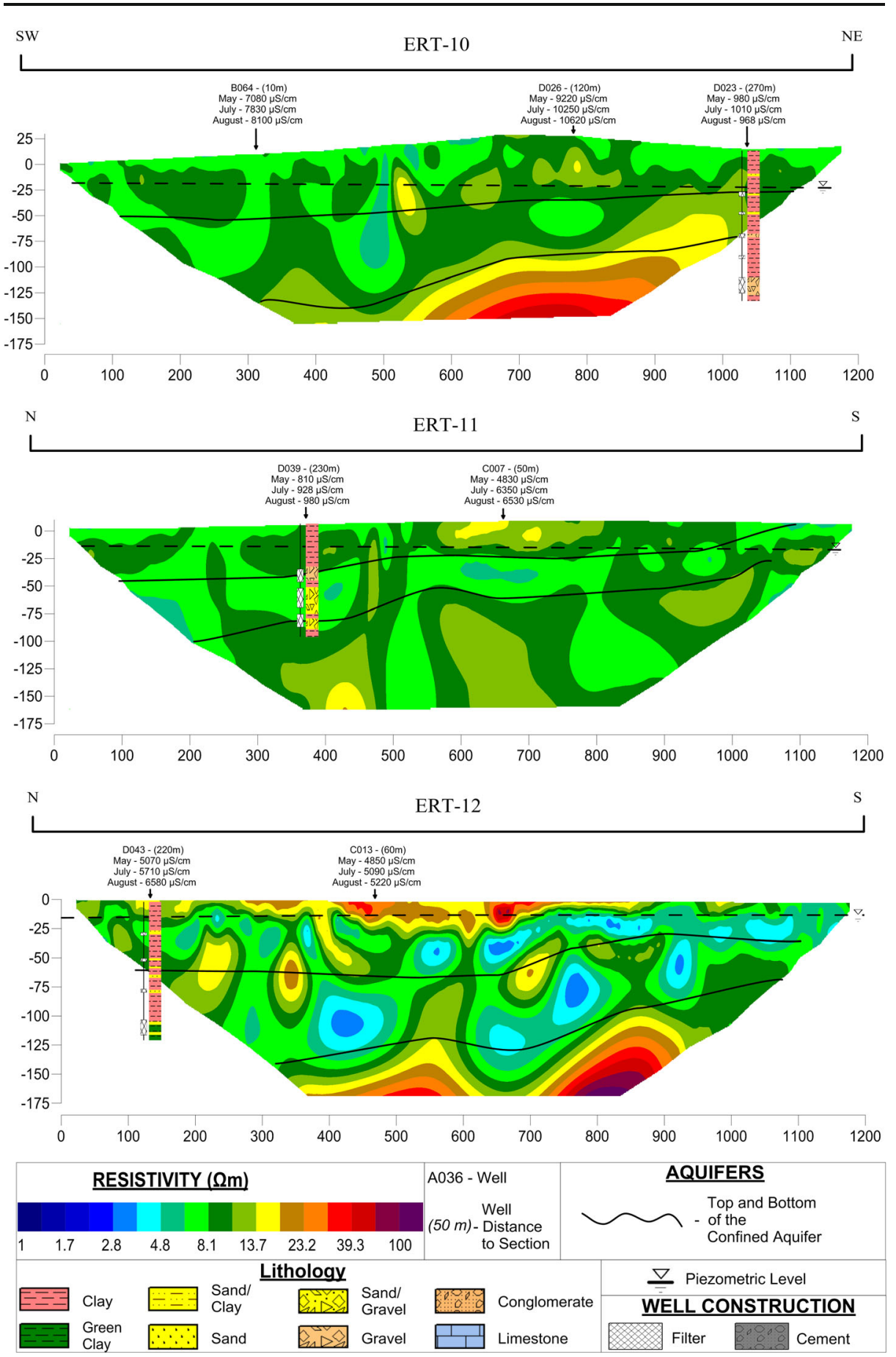

Fig. 6 Geoelectrical sections ERT10, ERT11 and ERT12 
High resolution interpretation of the ERT sections with the integration of lithological, physicochemical and geophysical log data enables the accurate identification of characteristic hydrogeological features, essential for the development of a detailed conceptual model. The natural saltwater 'tracer' causes abrupt resistivity changes between different groundwater quality aquifers or water masses, permitting the delineation of the salinity distribution, aquifer boundaries and hydrological interactions. Results revealed the presence of four major resistivity zones ranging in values between 0.1 and $150 \Omega \mathrm{m}$ at various depths and locations. A very low resistivity zone $(0.1-5 \Omega \mathrm{m})$ correlated with saline water saturated layers, a medium resistivity zone $(5-15 \Omega \mathrm{m})$ was attributed to clays and silts, and two high resistivity zones generally representing freshwater saturated sediments of coarse grain size $(15-40 \Omega \mathrm{m})$ or alterations of thin marl and fine sand layers $(40-150 \Omega \mathrm{m})$. Similar findings were identified in previous studies exploiting resistivity geophysical methods in saline groundwater contaminated areas (de Franco et al., 2009; Ogilvy et al., 2009; Zarroca et al., 2011; Ebraheem et al., 2012; Kafri et al., 2014). In all the aforementioned studies, saline water was correlated with very low apparent resistivity values (between 0.1 and $5 \Omega \mathrm{m}$ ) while slightly higher values were attributed to clays, and higher values $(>15 \Omega \mathrm{m})$ to freshwater saturated layers. Since resistivity measurements are dependent on both lithological properties of the aquifer and physicochemical characteristics of groundwater data, calibration could only be made possible through the presence of hydrogeological data. In the case of their absence, calibration can only be made through bibliographic references, while only a rough estimate of the aquifer system properties can be identified (e.g., number of aquifer layers, saline water distribution).

The 2D resistivity models show that resistivity values in the overall geophysically explored area range between 1 and $150 \Omega \mathrm{m}$, and spread in three resistivity zones which are evident in each ERT section. The uppermost zone consisting of low to medium resistivity values between 7 and $40 \Omega \mathrm{m}$, the intermediate zone consisting of very low resistivity values ( $<1$ to $7 \Omega \mathrm{m}$ ), and the bottom zone with medium to high resistivity values ranging between 12 and $150 \Omega \mathrm{m}$. Results show that in every modeled section, three discrete layers are evident based on the intense vertical resistivity contrast they present. This basic geoelectrical structure, although exhibits spatial variations on geometry and resistivity, is discrete in all 2D resistivity models and it is related to certain hydrogeological processes (saltwater intrusion, freshwater surface recharge) and the lithology of the aquifer system. Each layer corresponds to a separate aquifer unit, in accordance with the hydrogeological setting described. More specifically, the top layer represents the shallow semi-confined aquifer, the intermediate zone represents the main confined aquifer system, and the lower layer represents the deep confined aquifer.

Top layer resistivity profile can be separated into two large groups: the low resistivity group $(<12 \Omega \mathrm{m})$, representing mainly clay sediments with thin sand alterations, and the high resistivity group (12-40 $\Omega \mathrm{m}$ ), attributed to coarser sediments filled with freshwater. Spatial distribution of the low resistivity group shows that it dominates the largest portion of the semiconfined aquifer, while high resistivity measurements usually form lenses sporadically spread in the aquifer extent. Production wells drilled in these sediments (e.g., A018, A036) exhibit very low discharge rates $\left(5\right.$ to $10 \mathrm{~m}^{3} / \mathrm{h}$ ) or even completely fail to discharge at the end of the irrigation period. A shift from this continuous pattern is shown at the eastern end of section ERT1, full section ERT5 and at the western half of sections ERT6 and ERT7. At these neighboring locations, high resistivity values dominate the shallow semi-confined aquifer indicating the presence of freshwater reserves. Unfortunately, although there are quite a few wells screened between these intervals, there is limited knowledge regarding lithological content and hydraulic properties. Wells A056, A065 and A073 located in this aquifer portion exhibit intermediate discharge rates $\left(20-30 \mathrm{~m}^{3} / \mathrm{h}\right)$ of low electrical conductivity groundwater. The presence of surface hydrological features (streams, lagoons), shown in Fig. 1b, does not 
appear to significantly affect shallow aquifer recharge, as demonstrated by profiles ERT3 crossing Mikrorema stream and ERT6 aligned parallel to a segment of Mesi stream. Resistivity profile calibration shows that fine sediments (clays and silts) prevent surface water percolation to the shallow aquifer.

The intermediate layer corresponds to the main confined aquifer and exhibit extremely low resistivity values $(1-5 \Omega \mathrm{m})$ in sections ERT1, ERT2 and ERT12 orientated perpendicular to the study area hydraulic boundaries, attributed to hypersaline groundwater filled sediments of various grain sizes. Slightly higher resistivity values are displayed in sections ERT5, ERT6, ERT7 and ERT8, located at the area center. Profile ERT9, which is the only section deployed in the entirely fresh part of the aquifer, shows the key role of the saltwater natural 'tracer' in the application of the geoelectrical method. The absence of extreme resistivity contrasts incommodes stratigraphic interpretation and hydrogeological boundary delineation. Section ERT10 on the other hand shows the freshwater/saltwater interface extent, as it ends in the freshwater aquifer zone. The higher resistivity values at the beginning of the section can be explained through the small thickness of coarse sediments in this area prohibiting the wide electrode spacing tomography used in this study to capture aquifer pore salinity. Finally, sections ERT11 and ERT12 show very small variability in resistivity range and probably represent the dominance of clays and silts along with thin layers of saltwater filled sediments.

The deep confined unit is shown in every modeled section with intermediate to high resistivity values ranging between 30 and $150 \Omega \mathrm{m}$. Spatial distribution show that lower values are found closer to the study area edges, while higher measurements form a continuous horizontal line along sections ERT6, ERT7 and ERT8 center. Wells A013 projected in section ERT1 and B065 projected in section ERT7 are characteristic examples of well exploiting this aquifer. Cement rings are utilized to isolate deep aquifer sediments from the overlying downgraded main confined aquifer, and to prevent saltwater percolation through the borehole walls. Wells drilled at these depths generally exhibit low discharge rates of freshwater, which tend to significantly decrease at the end of the irrigation period due to the very slow recharge process.

\subsection{Conceptual Model Formulation}

In Fig. 7, the 2D ERT sections are projected on top of the study area background map, along with the main confined aquifer electrical conductivity spatial distribution. It is clearly shown that saltwater intrudes along an axis close to the inlet of Vistonis lagoon (sections ERT1 and ERT2) and proceeds eastward as shown in profiles ERT 6,7 and 8. On the southwest, aquifer basement elevation uplift along with the presence of a vertical freshwater recharge zone block the movement of saltwater by creating a vertical hydraulic barrier. Limited saline intrusion takes place across the south border except from the area close to Glyfada village, where very low resistivity values are measured (ERT12). Section ERT10 covers the limit of the saltwater extend towards the freshwater reserves close to Porpi village. The lateral abrupt change in resistivity between continuous sections ERT8 and ERT9 show that a sharp interface exists between saltwater and freshwater in the main confined aquifer. Deep aquifer sediments are present in every section depicting the main confined aquifer bottom limit. Interference between the shallow semi-confined and the main confined system takes place across a north to south oriented axis between Glykoneri and Mesi.

Vertical recharge between the three aquifer systems is possible where the impermeable clay layers separating them weakens, allowing groundwater to flow according to hydraulic gradient difference. Piezometric measurements have shown that water table elevation in the shallow semi-confined aquifer is approximately $10 \mathrm{~m}$ higher compared to the main confined aquifer. 


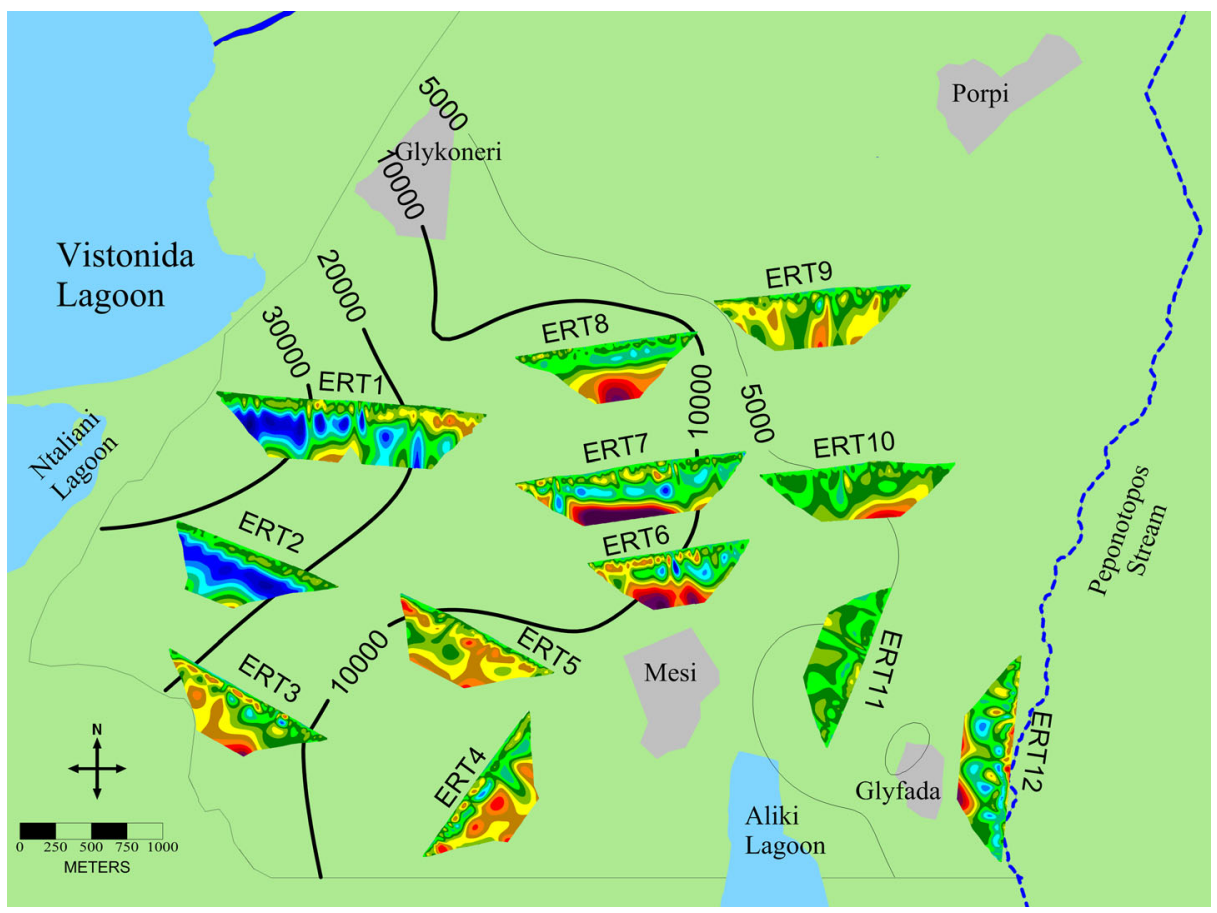

Fig. 7 2D ERT sections along with main confined aquifer electrical conductivity contours

As a result, groundwater from the shallow semi-confined aquifer recharges the main confined aquifer, a process clearly evident in the ERT sections (1-7-6 and 5) due to the groundwater quality difference between the two aquifers. High resistivity clusters are elongated across the vertical axis and disturb the continuance of the low resistivity zones at various locations causing mixing of different groundwater regimes. For example, well A016, although screened and isolated with cement rings in the main confined aquifer, exhibits lower conductivity values at the beginning of the irrigation period, compared to neighboring wells, due to the vertical freshwater recharge from the above aquifer. Another example is shown at section ERT5 between 600 to $800 \mathrm{~m}$, where a vertical high resistivity structure interrupts the low resistivity zone and unites the shallow semi-confined aquifer with the lower basement unit. The same feature is shown at the beginning of ERT section 6.

Regional upconing takes place at the end of the irrigation period, increasing pumping groundwater electrical conductivity, due to the depletion of the shallow aquifer resources and the improperly constructed wells. Well A018, although initially pumps at $2380 \mu \mathrm{S} / \mathrm{cm}$ at the beginning of the irrigation period, it ends up with approximately $16,000 \mu \mathrm{S} / \mathrm{cm}$ at the end, due to the depletion of fresh groundwater resources in the upper semi-confined aquifer, and the prevalence of the confined aquifer water masses in well quality characteristics.

Delineation of hydrogeological boundaries between the three aquifer systems is possible following the continuous line representing high resistivity contrast between them. Interruptions to this pattern occur due to freshwater recharge between the shallow semi-confined and the main confined aquifer system. Aquifer thickness mainly depends on basement fluctuations since the top boundary is almost flat. The basement is not shown as a continuous flat line but it forms fluctuations probably due to the presence of faults parallel to the known fault line, or 
because of the disturbed clay layer continuance through improperly constructed wells. In general terms, the confined aquifer bottom is located between -100 and $-150 \mathrm{~m}$ (a.m.s.l.) with the higher depths shown at section ERT2. In sections ERT3, ERT4 and ERT11, which are oriented close to the south system boundary, the aquifer basement depth significantly decreases. This upmoving is attributed to a major fault line parallel to the south boundary area limit, stressing the stratigraphic sequence upward. The vertical anomaly between 400 and $500 \mathrm{~m}$ in ERT4 can be attributed to a fault interference allowing saline water to percolate through the sediments. These connate groundwater reserves are very important for the sustainable groundwater management in the local area, since they represent the only sources of freshwater in a completely contaminated part of the area. Unfortunately, due to the high demand for fresh irrigation water and slow recharge rates, severe groundwater level drawdown is observed in the deep aquifer, which should be exclusively exploited only during drought periods.

\section{Conclusions}

The salinization of a multilayered coastal aquifer in Rhodope (Thrace, northeastern Greece) was studied by combined geophysical and hydrogeological surveys. The investigated area of $42 \mathrm{~km}^{2}$ exhibits gentle topography, is structured by Neogene-Quaternary alluvial formations, and is surrounded by Thracian sea, Vistonida lagoon, and other minor lagoons. Salinization phenomena were outlined by physicochemical measurements and piezometry observations over existing wells and a large scale ERT survey was designed in order to obtain a clear image. Twelve deep ERT profiles, $15 \mathrm{~km}$ of total length, with sufficient resolution were carried out. The inverted ERT data followed by low RMS error misfit, were compared to the physicochemical, lithological and well bore log data, and a good correlation was noted, which significantly reduced interpretation uncertainty. The $2 \mathrm{D}$ resistivity models revealed the presence of three major resistivity zones: the uppermost, low to medium resistivity layer which is correlated to the semi-confined aquifer with adequate freshwater resources; the highly conductive intermediate layer which corresponds to the main confined aquifer and the saltwater body; and the medium to high resistivity bottom layer which is attributed to the deep confined units. The geometry of the aquifer system, the hydraulic boundaries and the extent of the transition zone were estimated. The case study presented in this paper illuminates the mechanism of salinization of south Rhodope coastal aquifers, by combined use of large ERT and hydrogeological data sets. The proposed multidisciplinary approach seems to provide reliable information to build a realistic conceptual model for water management issues, contributing towards a rational and sustainable management of groundwater resources in environmentally sensitive areas.

\section{References}

Abdul Nassir SS, Loke MH, Lee CY, Nawawi MNM (2000) Salt-water intrusion mapping by geoelectrical imaging surveys. Geophys Prospect 48:647-661. doi:10.1046/j.1365-2478.2000.00209.x

Adepelumi A, Ako B, Ajayi T, Afolabi O, Omotoso E (2009) Delineation of saltwater intrusion into the freshwater aquifer of Lekki Peninsula, Lagos, Nigeria. Environ Geol 56:927-933. doi:10.1007/s00254008-1194-3

Archie GE (1942) The electrical resistivity log as an aid in determining some reservoir characteristics. Pet Trans AIME 146:54-62. doi:10.2118/942054-g

ASTM D6429-99 (2011) Standard Guide for selecting surface geophysical methods, ASTM International, West Conshohocken, PA, 2011, www.astm.org. doi: 10.1520/d6429 99r11e01 
Barker RD (1990) Investigation of groundwater salinity by geophysical methods. In: Ward S (ed) Geotechnical and Environmental Geophysics,vol 2. Society of Exploration Geophysicists, pp 201-212

Batayneh A (2006) Use of electrical resistivity methods for detecting subsurface fresh and saline water and delineating their interfacial configuration: a case study of the eastern Dead Sea coastal aquifers, Jordan. Hydrogeol J 14:1277-1283. doi:10.1007/s10040-006-0034-3

Bauer P, Supper R, Zimmermann S, Kinzelbach W (2006) Geoelectrical imaging of groundwater salinization in the Okavango Delta, Botswana. J Appl Geophys 60:126-141. doi:10.1016/j.jappgeo.2006.01.003

Bear J, Cheng AHD, Sorek S, Ouazar D, Herrera I (eds) (1999) Seawater intrusion in coastal aquifers - concepts, methods, and practices. (Theory and applications of transport in porous media, v. 14). Kluwer Academic Publishers, Dordrecht/Boston/London

Beltran JM (1999) Irrigation with saline water: benefits and environmental impact. Agric Water Manag 40:183194. doi:10.1016/S0378-3774(98)00120-6

Cassiani G, Bruno V, Villa A, Fusi N, Binley AM (2006) A saline trace test monitored via time-lapse surface electrical resistivity tomography. J Appl Geophys 59:244-259. doi:10.1016/j.jappgeo.2005.10.007

Choudhury K, Saha DK, Chakraborty P (2001) Geophysical study for saline water intrusion in a coastal alluvial terrain. J Appl Geophys 46:189-200. doi:10.1016/s0926-9851(01)00038-6

Dahlin T (2001) The development of DC resistivity imaging techniques. Comput Geosci 27:1019-1029. doi:10. 1016/s0098-3004(00)00160-6

de Franco R, Biella G, Tosi L, Teatini P, Lozej A, Chiozzotto B, Giada M, Rizzetto F, Claude C, Mayer A, Bassan V, Gasparetto-Stori G (2009) Monitoring the saltwater intrusion by time lapse electrical resistivity tomography: the Chioggia test site (Venice lagoon, Italy). J Appl Geophys 69:117-130. doi:10.1016/j. jappgeo.2009.08.004

Ebraheem A-AM, Senosy MM, Dahab KA (1997) Geoelectrical and hydrogeochemical studies for delineating ground-water contamination due to salt-water intrusion in the northern part of the Nile Delta, Egypt. Ground Water 35:216-222. doi:10.1111/j.1745-6584.1997.tb00077.x

Ebraheem AM, Sherif MM, Al Mulla MM, Akram SF, Shetty AV (2012) A geoelectrical and hydrogeological study for the assessment of groundwater resources in Wadi Al Bih, UAE. Environ Earth Sci 67:845-857. doi:10.1007/s12665-012-1527-0

Edet AE, Okereke CO (2001) A regional study of saltwater intrusion in southeastern Nigeria based on the analysis of geoelectrical and hydrochemical data. Environ Geol 40:1278-1289. doi:10.1007/s002540100313

Frohlich RK, Urish DW, Fuller J, O'Reilly M (1994) Use of geoelectrical methods in groundwater pollution surveys in a coastal environment. J Appl Geophys 32:139-154. doi:10.1016/0926-9851(94)90016-7

Galazoulas CE, Petalas PC (2014) Application of multivariate statistical procedures on major ions and trace elements in a multilayered coastal aquifer: the case of the south Rhodope coastal aquifer. Environ Earth Sci 72:4191-4205. doi:10.1007/s12665-014-3315-5

Gurunadha Rao VVS, Rao GT, Surinaidu L, Rajesh R, Mahesh J (2011) Geophysical and geochemical approach for seawater intrusion assessment in the Godavari Delta Basin, A.P., India. Water Air Soil Pollut 217:503514. doi:10.1007/s11270-010-0604-9

Hermans T, Vandenbohede A, Lebbe L, Martin R, Kemna A, Beaujean J, Nguyen F (2012) Imaging artificial salt water infiltration using electrical resistivity tomography constrained by geostatistical data. J Hydrol 438439:168-180. doi:10.1016/j.jhydrol.2012.03.021

Kafri U, Goldman M, Levi E, Wollman S (2014) Detection of saline groundwater bodies between the Dead Sea and the Mediterranean Sea, Israel, using the TDEM method and hydrochemical parameters Environ Process 1:21-41 doi:10.1007/s40710-014-0001-2

Leitão T, Mota R, Novo M, Lobo-Ferreira J (2014) Combined use of electrical resistivity tomography and hydrochemical data to assess anthropogenic impacts on water quality of a karstic region: a case study from Querença-Silves, South Portugal Environ Process 1:43-57. doi:10.1007/s40710-014-0002-1

Loke MH, Barker RD (1996) Rapid least square inversion of apparent resistivity pseudosections using quasiNewton method. Geophys Prospect 44:131-152. doi:10.1111/j.1365-2478.1996.tb00142.x

Maillet GM, Rizzo E, Revil A, Vella C (2005) High resolution electrical resistivity tomography (ERT) in a transition zone environment: application for detailed internal architecture and infilling processes study of a Rhône river paleo-channel. Mar Geophys Res 26:317-328. doi:10.1007/s11001-005-3726-5

Martínez J, Benavente J, García-Aróstegui JL, Hidalgo MC, Rey J (2009) Contribution of electrical resistivity tomography to the study of detrital aquifers affected by seawater intrusion-extrusion effects: the river Vélez delta (Vélez-Málaga, southern Spain). Eng Geol 108:161-168. doi:10.1016/j.enggeo.2009.07.004

Mas-Pla J, Rodríguez-Florit A, Zamorano M, Roqué C, Menció A, Brusi D (2012) Anticipating the effects of groundwater withdrawal on seawater intrusion and soil settlement in urban coastal areas. Hydrol Process 27: 2352-2366. doi:10.1002/hyp.9377 
Morrow FJ, Ingham MR, McConchie JA (2010) Monitoring of tidal influences on the saline interface using resistivity traversing and cross-borehole resistivity tomography. J Hydrol 389:69-77. doi:10.1016/j.jhydrol. 2010.05.022

Nowroozi AA, Horrocks SB, Henderson P (1999) Saltwater intrusion into the freshwater aquifer in the eastern shore of Virginia: a reconnaissance electrical resistivity survey. J Appl Geophys 42:1-22. doi:10.1016/ s0926-9851(99)00004-x

Ogilvy RD, Meldrum PI, Kuras O, Wilkinson PB, Chambers JE, Sen M, Pulido-Bosch A, Gisbert J, Jorreto S, Frances I, Tsourlos P (2009) Automated monitoring of coastal aquifers with electrical resistivity tomography. Near Surf Geophys 7:367-375. doi:10.3997/1873-0604.2009027

Perri MT, Cassiani G, Gervasio I, Deiana R, Binley A (2012) A saline tracer test monitored via both surface and cross-borehole electrical resistivity tomography: comparison of time-lapse results. J Appl Geophys 79:6-16. doi:10.1016/j.jappgeo.2011.12.011

Petalas CP (1997) Analysis of aquifer systems in the heterogeneous coastal part of prefecture of Rhodope. PhD Dissertation. Department of Civil Engineering, Democritus University of Thrace. (In Greek)

Petalas CP, Diamantis JV (1999) Origin and distribution of saline groundwaters in the upper Miocene aquifer system, coastal Rhodope area, northeastern Greece. Hydrogeol J 7:305-316. doi:10.1007/s100400050204

Petalas C, Lambrakis N (2006) Simulation of intense salinization phenomena in coastal aquifers - the case of the coastal aquifers of Thrace. J Hydrol 324:51-64. doi:10.1016/j.jhydrol.2005.09.031

Petalas C, Pisinaras V, Gemitzi A, Tsihrintzis VA, Ouzounis K (2009) Current conditions of saltwater intrusion in the coastal Rhodope aquifer system, northeastern Greece. Desalination 237:22-41

Pisinaras V, Tsihrintzis V, Petalas C, Ouzounis K (2010) Soil salinization in the agricultural lands of Rhodope District, northeastern Greece. Environ Monit Assess 166:79-94. doi:10.1007/s10661-009-0986-6

Ranjan SP, Kazama S, Sawamoto M (2006) Effects of climate and land use changes on groundwater resources in coastal aquifers. J Environ Manag 80:25-35. doi:10.1016/j.jenvman.2005.08.008

Reynolds JM (2011) An introduction to Applied Geophysics. (2nd Edition), Wiley-Blackwell

Rubin Y, Hubbard SS (2005) Hydrogeophysics. Springer, Netherlands

Sherif M, Mahmoudi A, Garamoon H, Kacimov A, Akram S, Ebraheem A, Shetty A (2006) Geoelectrical and hydrogeochemical studies for delineating seawater intrusion in the outlet of Wadi Ham, UAE. Environ Geol 49:536-551. doi:10.1007/s00254-005-0081-4

Singha K, Gorelick SM (2005) Saline tracer visualized with three-dimensional electrical resistivity tomography: field-scale spatial moment analysis. Water Resour Res 41, W05023. doi:10.1029/2004wr003460

Telford WM, Geldart LP, Sheriff RE (1990) Applied Geophysics. Cambridge University Press

Todd DK (1980) Groundwater Hydrology. John Wiley and Sons.

Tuong TP, Kam SP, Hoanh CT, Dung LC, Khiem NT, Barr J, Ben DC (2003) Impact of seawater intrusion control on the environment, land use and household incomes in a coastal area. Paddy Water Environ 1:6573. doi:10.1007/s10333-003-0015-2

Urish DW, Frohlich RK (1990) Surface electrical resistivity in coastal groundwater exploration. Geoexploration 26:267-289. doi:10.1016/0016-7142(90)90008-g

Wilson SR, Ingham M, McConchie JA (2006) The applicability of earth resistivity methods for saline interface definition. J Hydrol 316:301-312. doi:10.1016/j.jhydrol.2005.05.004

Zarroca M, Bach J, Linares R, Pellicer XM (2011) Electrical methods (VES and ERT) for identifying, mapping and monitoring different saline domains in a coastal plain region (Alt Empordà, Northern Spain). J Hydrol 409:407-422. doi:10.1016/j.jhydrol.2011.08.052 